\title{
Analysis of the perception of motion concomitant with a lateral motion of the head
}

\author{
WALTER C. GOGEL \\ University of California, Santa Barbara, California
}

\begin{abstract}
This study is concerned with two questions regarding the illusory motion of objects that occurs concomitantly with motion of the head. One is whether this illusory concomitant motion, unlike the perception of real motion, is paradoxical in the sense that, although the object appears to move, it does not appear to go anywhere. The second question is whether illusory concomitant motion can be explained by errors in convergence produced by a tendency for the convergence of the eyes to displace in the direction of the resting state of convergence. Both questions receive a negative answer. In Experiment 1, it is shown that the illusory motion perceptually can add to or subtract from apparent motion resulting from real motion. In Experiment 2, it is shown that, for a binocularly viewed object at a near distance, the error in convergence (fixation disparity) is far too small to be an explanation for the illusory object motion associated with a moving head. The results of both experiments support an interpretation of illusory concomitant motion in terms of errors in the apparent distance of the stimulus object and the veridical perception of its direction.
\end{abstract}

There is considerable evidence that an error in the perceived distance of a physically stationary object viewed during a lateral motion of the head results in the perception that the object is moving laterally (see Gogel, 1981, for a review of this evidence). As described in the caption of Figure 1 and as discussed elsewhere (Gogel, 1976, 1977; Gogel \& Tietz, 1979), the apparent motion of the object is in the same direction as or in the direction opposite to the head motion, depending upon whether the perceived distance of the object is less or greater, respectively, than its physical distance. Shebilske and Proffitt (1981) doubted that this apparent motion is the same as that resulting from a physical motion. They asserted that the apparent motion of stationary objects concomitant with a head motion is paradoxical in the sense that the objects "appear to move without going anywhere" (p. 170). The primary purpose of Experiment 1 in the present study was to examine this assertion. The question was whether apparent concomitant motion resulting from an error in perceived distance (an illusory motion) is perceptually distinguishable from that resulting from a physical (nonillusory) motion of the object as the head is moved. Experiment 1 provided a negative answer. Experiment 2 evaluated an explanation for the error in perceived distance found in Experiment 1 for the

This investigation was supported by a general research grant from the Academic Senate of the University of California. The author wishes to thank Jerome D. Tietz for his assistance in building the apparatus and in collecting and analyzing the data. The author's mailing address is: Department of Psychology, University of California, Santa Barbara, California 93106. case in which the convergence distance and physical distance to the object were the same. The explanation that was to be evaluated derived from a study by Owens and Leibowitz (1976). According to that study, an error in fixation (fixation disparity) in the direction of the resting state of convergence is expected for a binocularly viewed point presented in a dark surround, with this fixation error producing the error in apparent distance and in apparent concomitant motion. In Experiment 2, the magnitude of the fixation disparity was found to be far too small to explain the measured errors in perceived distance or in apparent motion.

\section{EXPERIMENT 1}

\section{Method}

To test the perceptual equivalence of illusory and nonillusory apparent concomitant motions, different amounts of both of these were generated and measured, using a point of light presented in an otherwise dark visual field. Nonillusory concomitant motions were generated by physically moving a point of light concomitantly with a lateral motion of the head. Illusory concomitant motions were produced by errors in perceived distance. An error in perceived distance occurs if a physically stationary point of light is presented at a near distance. Even with binocular observation, the point appears at a greater distance than its physical distance and, as illustrated in Figure 1B, it appears to move in the direction opposite to that of the head motion (Gogel, 1977; Gogel \& Tietz, 1973, 1979). This error in perceived distance can be modified systematically, without changing the physical distance of the point, by changing the amount of convergence required to binocularly fuse the images of the point on the two eyes. Both nonillusory and illusory motions were used in Experiment 1.

The magnitude of the apparent concomitant motion in Experiment 1 was measured in two ways. One way, the pointing pro- 


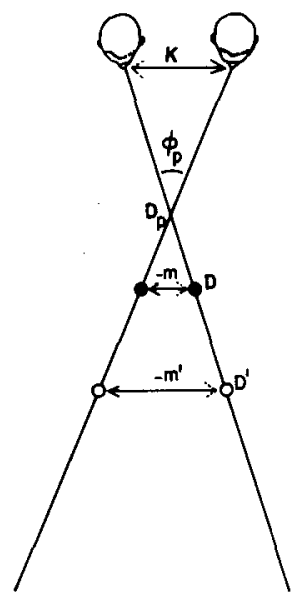

A

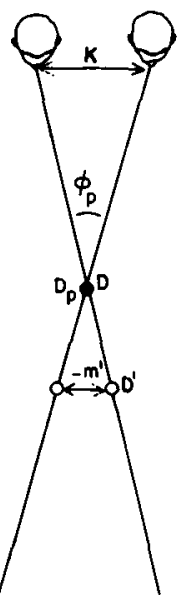

B

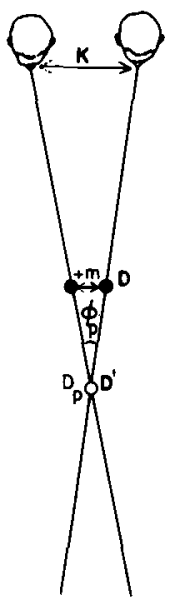

C

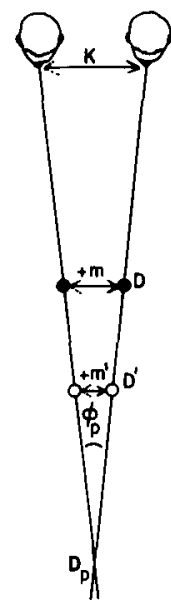

D

Figure 1. A top view schematic diagram illustrating the effect of different physical lateral motions (m) of a point of light concomitant with a constant lateral motion $(K)$ of the head upon its perceived concomitant motion $(m$ ') for a constant physical (D) and perceived (D') distance of the point from the observer. The prime notations and open circles indicate apparent characteristics of the point; the notations without primes and the filled circles indicate physical characteristics. The situation illustrated is one in which the observer views a point of light while moving his head right and left repetitively. The lines connecting the point of light and the position of the observer are construction lines to indicate the direction of the point of light from the observer for the two extremes of head position. The intersection of the direction lines is a hypothetical point around which the direction to the object pivots as the head is moved laterally, The distance of the pivot from the observer is called the pivot distance $\left(D_{p}\right)$, and $\phi_{p}$ is the pivot angle. For $a$ given $D, D_{p}$ depends upon $m$, with $D_{p}=D$ when $m=0$ and $D_{p}=D^{\prime}$ when $m^{\prime}=0$. A plus value of $m$ or $m^{\prime}$ means that the lateral motion (real or illusory) of the point is in the same direction as the head motion, and a minus $m$ or $m$ ' means that the lateral motion of the point is opposite to that of the head motion. It can be shown from the geometry of Figure 1 that

$$
\mathbf{m}^{\prime}=\mathbf{K}\left(1-\mathbf{D}^{\prime} / \mathbf{D}_{\mathbf{p}}\right)
$$

The dependence of $m^{\prime}$ upon $D^{\prime} / D_{p}$ for a constant value of $K$ is called the apparent-distance/pivot-distance hypothesis. Although Equation 1 is the most parsimonious expression of the factors determining $\mathrm{m}^{\prime}$, a useful equation for applying the apparent-distance /pivotdistance hypothesis is

$$
\mathbf{m}^{\prime}=\left(\mathbf{K D}-\mathbf{K D} \mathbf{D}^{\prime}+\mathbf{m} \mathbf{D}^{\prime}\right) / \mathbf{D}
$$

Thus, given the physical terms $\mathbf{K}, \mathbf{D}$, and $\mathrm{m}$ and the perceived distance $\mathbf{D}^{\prime}, \mathrm{m}^{\prime}$ can be predicted. Also, given $\mathbf{K}, \mathbf{D}$, and $\mathrm{m}$ and the perceived motion $\mathrm{m}^{\prime}, \mathrm{D}^{\prime}$ can be predicted from Equation 2 as follows:

$$
\mathbf{D}^{\prime}=\mathbf{D}\left(\mathbf{K}-\mathbf{m}^{\prime}\right) /(\mathbf{K}-\mathbf{m}) \text {. }
$$

Furthermore, if $m^{\prime}=0$, it follows that

$$
\mathbf{D}^{\prime}=\mathbf{K D} /(\mathbf{K}-\mathbf{m}) \text {. }
$$

According to Equation 4, if the physical motion $(m)$ of the point is adjusted until the point appears to be stationary $(m '=0)$ as the head is moved, the $D^{\prime}$ of the point can be calculated. Finding $D^{\prime}$ by adjusting $m$ until $m^{\prime}=0$ is called the null adjustment; this procedure is illustrated in Figure 1C. It is evident that $D^{\prime}$ can be measured indirectly either by directly measuring $\mathrm{m}^{\prime}$ (Equation 3 ) or by adjusting $\mathrm{m}$ until $\mathrm{m}^{\prime}=0$ (Equation 4). An assumption basic to Equations 1-4 is that the change in perceived direction of the stimulus object per unit of head motion is veridical. This assumption could be avoided If Equation 1 were written $a s m^{\prime}=K^{\prime}\left(1-D^{\prime} / D_{p}^{\prime}\right)$. In this case, however, the experimental test of the equation would be very cumbersome. Fortunately, as indicated by the present study, the assumption regarding the veridicality of perceived direction seems to be valid.

cedure, was to point with an unseen hand beneath the perceived position of the point of light at the extreme right and left positions of the head. In the other, the hand adjustment procedure, the lateral visual separation of comparison posts was adjusted by the observer to match the perceived lateral motion of the point.

\section{Observers}

Six observers (four men and two women) were used in Experiment 1 . Four were graduate and two were undergraduate students in psychology who were paid for their participation. Each had a near and far acuity of $20 / 20$ without glasses or contact lenses and a binocular acuity of at least $25 \mathrm{sec}$ of arc. Three of these had been in previous experiments involving a head motion. Prior to their participation, none were aware of the purpose of the present study.

\section{Apparatus}

Head-motion apparatus. The observer sat in a dark room and binocularly viewed a point of light presented on a CRT display scope through an aperture $(29 \mathrm{~cm}$ wide $\times 5.7 \mathrm{~cm}$ high) that could 
be occluded by the experimenter. A replaceable bite-board formed by a tongue depressor was mounted on a cart that could be moved repetitively left and right on ball bearings through a distance of $21.2 \mathrm{~cm}$. A hard rubber knob on the cart positioned the head and located the eyes of the observer at the proper distance $(25 \mathrm{~cm})$ from the point of light. The observer moved the cart laterally in front of the viewing aperture by means of the bite-board. Cushioned stops at the left and right limited the lateral motion of the cart. A rack-and-pinion gear located on the track of the cart rotated the shaft of a linear potentiometer as a function of the lateral position of the cart and head. The voltage from the potentiometer was sent to a Declab PDP-11/03 computer, with the output of the computer controlling the position of the point on the display scope. A computer program allowed the relation between the head position and the position of the point on the scope to be changed by the observer's or experimenter's turning a control knob connected to another potentiometer. By means of the control knob, the physical motion of the point of light concomitant with the motion of the head could be adjusted to any magnitude (including zero motion) either in the same direction as or in the opposite direction to the motion of the head.

The display. A point of light physically at $25 \mathrm{~cm}$ from the observer had a convergence distance of either 25 or $40 \mathrm{~cm}$. The convergence to the point (with accommodation unchanged) was modified by placing polarizing material on the display surface and in goggles worn by the observer. Two horizontally oriented strips of Polaroid with opposite axes of polarization were positioned on the display surface, one directly above the other. Two points of light, one behind the upper and the other behind the lower Polaroid strips, were presented simultaneously. The axes of polarization in the goggles were such that the upper point was seen only by the left eye and the lower point only by the right eye. In order to vertically align the two points for binocular fusion, a 5-diopter wedge prism was located in the left eyepiece of the goggles. For the convergence to $25 \mathrm{~cm}$, the upper point was always directly above the lower point. For the convergence to $40 \mathrm{~cm}$ (with the physical distance remaining at $25 \mathrm{~cm}$ ), the two points were separated left and right by the necessary amount, calculated separately for each observer's interocular distance.

The point of light was viewed through a red filter to eliminate visibility of the phosphor trace on the scope for the conditions in which the point was moved physically left and right. The point of light, when fused binocularly, was at eye level and was approximately $.5 \mathrm{log}$ units above foveal threshold under the adaptation conditions of the experiment. When the point of light was being observed, no other object or surface was visible. In the headmoving conditions, the point physically moved repetitively left and right, concomitantly with the head motion, around the center of the path of motion of the head. This motion of the point was $5.08 \mathrm{~cm}$ in the direction opposite to that of the head motion (called $-5.08 \mathrm{~cm}$ ), $10.16 \mathrm{~cm}$ in the same direction as the head motion (called $+10.16 \mathrm{~cm}$ ), or physically stationary (zero physical motion). In the head-stationary condition, the point of light physically moved symmetrically and repetitively left and right of the centered observation position through a distance of either 5.08 or $10.16 \mathrm{~cm}$.

The measurement of perceived distance and direction. The CRT for presenting the point of light rested on a wooden floor extending from the observation position. The apparatus for the pointing procedure was below this floor and no part of this apparatus or of the observer's hand could be seen by the observer during the pointing. The pointer was a vertical rod $.5 \mathrm{~cm}$ in diameter and $11.3 \mathrm{~cm}$ long, with the top $7.0 \mathrm{~cm}$ below the level of the point of light. The observer grasped the rod with the preferred hand, placing the thumb at or slightly above the top. The rod was movable $57 \mathrm{~cm}$ left or right along a horizontal beam parallel to the observer's frontal plane. This beam was movable between 18 and $63 \mathrm{~cm}$ in distance. Thus, the observer could move the pointer to any position within an area $57 \mathrm{~cm}$ wide and $45 \mathrm{~cm}$ in depth.

The left-right position and the depth position of the pointer were connected independently to linear potentiometers that modulated the voltage input to the computer. These voltages were recorded in the computer whenever the observer (using the nonpreferred hand) pressed a button located near the observation position.

A hand adjustment apparatus also was available to measure the apparent lateral motion of the point of light. This apparatus consisted of two vertical bars, $.5 \mathrm{~cm}$ square in cross section and $5.0 \mathrm{~cm}$ high, located near the lap of the observer. The observer was able to move the right bar laterally to indicate, by the separation of the inner surfaces of the bars, the extent of apparent left-right motion of the point of light. The bars were made visible to the observer when a light in the observation position was turned on after the aperture through which the point of light had been viewed was occluded.

The perceived distance of the point of light was measured by the procedure indicated in Figure $1 \mathrm{C}$, as well as by the pointing procedure. For this purpose, the observer adjusted the physical lateral motion of the point by turning the control knob located near the observation position until the point appeared stationary (the null adjustment) as the head was moved laterally. This was accomplished using a bracketing technique in which the null condition was approached from successively smaller knob adjustments alternately "against" and "with" the head motion. The observer pressed a button to register the final setting of the knob in the computer.

\section{Procedure}

Orders of presentations. There were three factors in the experiment, each of which had several conditions. These were: (1) whether the head was stationary or moving, (2) whether the physical motion of the point of light on the display was $-5.08,0.0$, or +10.16 $\mathrm{cm}$ comcomitant with the head motion, for the head-moving condition, and 5.08 or $10.16 \mathrm{~cm}$ for the head-stationary condition, and (3) whether the convergence to the point of light, physically at $25 \mathrm{~cm}$, was to 25 or $40 \mathrm{~cm}$. All observers received all of the stimulus conditions, and the order in which the conditions within each factor were presented was counterbalanced between observers. Also, there were three measurement procedures. These were: (1) the pointing procedure, (2) the hand adjustment procedure, and (3) the null adjustment procedure. For a particular convergence condition, the hand adjustment procedure always followed the pointing procedure, with two null adjustments completed only after all the conditions for a particular convergence had been presented. After the data from the first presentation of all the conditions had been obtained, the conditions were presented again in the same order so as to double the number of responses.

Head-moving conditions. To pace the lateral motion of the head, a buzzer sounded every $1.5 \mathrm{sec}$ for a duration of $1.5 \mathrm{sec}$ The observer was instructed to move his head repetitively between the left and right stops during the intervals of silence and to remain at the stops for the duration of the buzzer sound. This pause at the extremes of head motion provided time for the observer to position the pointer directly beneath the apparent location of the point of light at the extreme of its apparent motion to the right or left. This was accomplished for half the observers first at the far left and then at the far right position. For the other half of the observers, this order was reversed. The observer was encouraged to use as many cycles of head motion as necessary to achieve an adjustment of the pointer to a particular extreme of apparent motion. For example, for a particular observer, the adjustment to the left apparent position of the point might have been approximated on the first cycle of head motion, modified on the second, and confirmed on the third cycle. Next, the observer pressed the button to record the lateral and distance position of the pointer in the computer, with this process repeated for the far right position of apparent motion.

After having indicated both positional extremes of apparent motion for a particular convergence and a particular amount of physical concomitant motion of the point (including the condition in which the point was physically stationary), the observer again viewed the apparent motion concomitant with head motion until a clear perception of the lateral extent of motion was obtained 
(a task usually requiring two or three cycles of head motion). Next, the viewing aperture was occluded and the light in the observation booth was turned on. After lifting the goggles, the observer adjusted the separation of the inner surfaces of the posts of the hand adjustment apparatus (using a bracketing technique) to indicate the extent of lateral motion perceived in the point.

Upon completing the pointing and hand adjustments for a particular value of convergence with the head moving and the three physical concomitant motions of $-5.08,0.0$, and $+10.16 \mathrm{~cm}$, the observer completed two successive adjustments of the knob to the criterion of no apparent motion of the point (the null adjustment) as the head was moved repetitively left and right.

Head-stationary conditions. For the head-stationary conditions, the cart and bite-board were pinned at the center of the motion used with the head-moving conditions. The point of light moved repetitively 5.08 or $10.16 \mathrm{~cm}$ horizontally on the display screen in $1.5 \mathrm{sec}$, with 1.5-sec pauses at the left and right extremes of motion, as controlled by the computer. The observer used several repetitive cycles of point motion to adjust the pointer directly below first one extreme of motion and then the other, as in the case of the head-moving conditions. Following this, the hand adjustment apparatus again was used to measure the apparent lateral motion of the point.

All tasks (pointing, hand adjustment, or null adjustment) were completed first at one convergence distance and then at the other. Both convergence distances were presented with one type of head condition (stationary or moving) before presenting the other condition.

\section{Results}

The apparent lateral motion of the point of light as measured with the pointing and hand adjustment procedures is shown in Table 1. Each observer's score is the average of two measures obtained under the conditions noted in the column headings. Each point- ing measure is the lateral difference between left and right pointing. Consistent with Figure 1, physical (m) and apparent $\left(\mathrm{m}^{\prime}\right)$ concomitant motion of the point of light are given a plus sign if they are in the same direction as the head motion and a minus sign if opposite in direction to the head motion. Unlike concomitant motions, the repetitive left-right motions of the point viewed with the head stationary are unsigned. Consider the $m^{\prime}$ result obtained from observation with the head moving. For the condition in which the point was physically stationary $(m=0)$, all six observers, when asked to point directly below the point, pointed to a different physical lateral position at the two extremes of head motion (average $\mathrm{m}^{\prime}=$ $-7.2 \mathrm{~cm}$ for the $25-\mathrm{cm}$ convergence and $-13.3 \mathrm{~cm}$ for the 40-cm convergence). Also, the effect of this illusory motion did not disappear when physical motion was added to the point. Indeed, $-5.08 \mathrm{~cm}$ of nonillusory motion in the same direction as the illusory motion often resulted in a greater absolute amount of apparent motion than did $+10.16 \mathrm{~cm}$ of nonillusory motion in the direction opposite to the illusory motion, for both the 25 - and $40-\mathrm{cm}$ distances of convergence. These results are inconsistent with the assertion by Shebilske and Proffitt (1981) that illusory motion concomitant with a motion of the head is paradoxical in the sense that it appears to move without going anywhere. Instead, the illusory and nonillusory motion combine in their effect on motion perception. The pattern of results from the hand adjustment procedure is similar to that from the point-

Table 1

Results From Experiment 1: Apparent Lateral Motion (in Centimeters) of the Point of Light, as Measured by Pointing and Hand Adjustment Procedures, for the Moving and Stationary Head Conditions as a Function of the Physical Lateral Motion (m) and the Convergence Distance (CD; in Centimeters) of the Point

\begin{tabular}{|c|c|c|c|c|c|c|c|c|c|c|}
\hline \multirow[b]{3}{*}{ Observer } & \multicolumn{6}{|c|}{ Moving Head } & \multicolumn{4}{|c|}{ Stationary Head } \\
\hline & \multicolumn{2}{|c|}{$\mathrm{m}=-5.08 \mathrm{~cm}$} & \multicolumn{2}{|c|}{$\mathrm{m}=0 \mathrm{~cm}$} & \multicolumn{2}{|c|}{$\mathrm{m}=+10.16 \mathrm{~cm}$} & \multicolumn{2}{|c|}{$\mathrm{m}=5.08 \mathrm{~cm}$} & \multicolumn{2}{|c|}{$\mathrm{m}=10.16 \mathrm{~cm}$} \\
\hline & $C D=25$ & $C D=40$ & $\mathrm{CD}=25$ & $C D=40$ & $\mathrm{CD}=25$ & $\mathrm{CS}=40$ & $\mathrm{CD}=25$ & $\mathrm{CD}=40$ & $\mathrm{CD}=40$ & $\mathrm{CD}=25$ \\
\hline & \multicolumn{10}{|c|}{ Pointing Procedure } \\
\hline $\begin{array}{l}1 \\
2 \\
3 \\
4 \\
5 \\
6\end{array}$ & $\begin{array}{l}-19.0 \\
-6.4 \\
-11.8 \\
-10.0 \\
-7.7 \\
-4.8\end{array}$ & $\begin{array}{l}-27.8 \\
-18.2 \\
-20.9 \\
-22.6 \\
-11.3 \\
-20.2\end{array}$ & $\begin{array}{l}-11.4 \\
-3.4 \\
-11.2 \\
-3.3 \\
-11.8 \\
-1.8\end{array}$ & $\begin{array}{l}-21.0 \\
-15.9 \\
-12.5 \\
-13.4 \\
-6.2 \\
-10.8\end{array}$ & $\begin{array}{l}+4.7 \\
+10.2 \\
+7.2 \\
+1.1 \\
+8.4 \\
+10.4\end{array}$ & $\begin{array}{r}-4.2 \\
+2.5 \\
-4.8 \\
-.8 \\
-.2 \\
+5.5\end{array}$ & $\begin{array}{l}9.9 \\
8.0 \\
6.0 \\
5.6 \\
5.6 \\
7.1\end{array}$ & $\begin{array}{r}15.3 \\
11.1 \\
6.8 \\
9.2 \\
6.4 \\
7.8\end{array}$ & $\begin{array}{l}21.2 \\
13.4 \\
14.4 \\
14.6 \\
13.2 \\
13.2\end{array}$ & $\begin{array}{l}25.1 \\
18.5 \\
22.6 \\
21.4 \\
12.9 \\
18.0\end{array}$ \\
\hline $\begin{array}{l}\text { Mean } \\
\text { SD }\end{array}$ & $\begin{array}{r}9.9 \\
5.1\end{array}$ & $\begin{array}{r}-20.2 \\
5.4\end{array}$ & $\begin{array}{r}-7.2 \\
4.8\end{array}$ & $\begin{array}{r}-13.3 \\
5.0\end{array}$ & $\begin{array}{r}7.0 \\
3.6\end{array}$ & 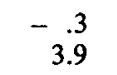 & $\begin{array}{l}7.0 \\
1.7\end{array}$ & $\begin{array}{l}9.4 \\
3.3\end{array}$ & $\begin{array}{r}15.0 \\
3.1\end{array}$ & $\begin{array}{r}19.8 \\
4.3\end{array}$ \\
\hline $\begin{array}{l}1 \\
2 \\
3 \\
4 \\
5 \\
6\end{array}$ & $\begin{array}{l}-15.6 \\
-20.5 \\
-11.5 \\
-13.0 \\
-21.0 \\
-22.5\end{array}$ & $\begin{array}{l}-27.5 \\
-31.8 \\
-21.6 \\
-18.8 \\
-29.0 \\
-34.9\end{array}$ & $\begin{array}{l}-10.5 \\
-13.9 \\
-8.8 \\
-9.3 \\
-19.2 \\
-15.2\end{array}$ & $\begin{array}{r}\text { Han } \\
-18.2 \\
-28.2 \\
-15.2 \\
-17.6 \\
-25.8 \\
-23.4\end{array}$ & $\begin{array}{l}\text { Adjustmen } \\
\begin{array}{l}+\quad .6 \\
+12.4 \\
+4.2 \\
+\quad .4 \\
+10.8 \\
+11.6\end{array}\end{array}$ & $\begin{array}{l}\text { Procedure } \\
\begin{array}{c}-1.7 \\
+1.2 \\
-4.4 \\
-3.0 \\
-1.3 \\
+9.8\end{array}\end{array}$ & $\begin{array}{r}7.6 \\
9.3 \\
5.0 \\
4.4 \\
10.0 \\
5.1\end{array}$ & $\begin{array}{r}7.8 \\
17.0 \\
9.7 \\
5.6 \\
11.8 \\
10.0\end{array}$ & $\begin{array}{r}15.4 \\
18.8 \\
9.4 \\
7.6 \\
16.0 \\
14.7\end{array}$ & $\begin{array}{l}21.4 \\
26.3 \\
18.4 \\
13.2 \\
23.8 \\
17.4\end{array}$ \\
\hline $\begin{array}{l}\text { Mean } \\
\text { SD }\end{array}$ & $\begin{array}{r}-17.4 \\
4.6 \\
\end{array}$ & $\begin{array}{r}-27.3 \\
6.1 \\
\end{array}$ & $\begin{array}{r}-12.8 \\
4.0 \\
\end{array}$ & $\begin{array}{r}-21.4 \\
5.2 \\
\end{array}$ & $\begin{array}{r}6.7 \\
5.6 \\
\end{array}$ & $+\begin{array}{r}.1 \\
5.1\end{array}$ & $\begin{array}{l}6.9 \\
2.4 \\
\end{array}$ & $\begin{array}{r}10.3 \\
3.9 \\
\end{array}$ & $\begin{array}{r}13.7 \\
4.2 \\
\end{array}$ & $\begin{array}{r}20.1 \\
4.7\end{array}$ \\
\hline
\end{tabular}


Table 2

Results From Experiment 1 : Apparent Distance (in Centimeters) of the Point of Light, as Measured by Pointing, for the Moving and Stationary Head Condition as a Function of the Physical Lateral Motion (m) and Convergence Distance (CD; in Centimeters) of the Point

\begin{tabular}{|c|c|c|c|c|c|c|c|c|c|c|}
\hline \multirow[b]{3}{*}{ Observer } & \multicolumn{6}{|c|}{ Moving Head } & \multicolumn{4}{|c|}{ Stationary Head } \\
\hline & \multicolumn{2}{|c|}{$\mathrm{m}=-5.08 \mathrm{~cm}$} & \multicolumn{2}{|c|}{$\mathrm{m}=0 \mathrm{~cm}$} & \multicolumn{2}{|c|}{$\mathrm{m}=+10.16 \mathrm{~cm}$} & \multicolumn{2}{|c|}{$\mathrm{m}=5.08 \mathrm{~cm}$} & \multicolumn{2}{|c|}{$\mathrm{m}=10.16 \mathrm{~cm}$} \\
\hline & $\mathrm{CD}=25$ & $\mathrm{CD}=40$ & $\mathrm{CD}=25$ & $\mathrm{CD}=40$ & $\mathrm{CD}=25$ & $\mathrm{CS}=40$ & $\mathrm{CD}=25$ & $C D=40$ & $\mathrm{CD}=25$ & $\mathrm{CD}=40$ \\
\hline $\begin{array}{l}1 \\
2 \\
3 \\
4 \\
5 \\
6\end{array}$ & $\begin{array}{l}37.9 \\
31.6 \\
26.9 \\
36.5 \\
31.6 \\
30.9\end{array}$ & $\begin{array}{l}45.6 \\
42.5 \\
35.2 \\
50.5 \\
39.4 \\
48.2\end{array}$ & $\begin{array}{l}39.3 \\
32.2 \\
28.6 \\
37.0 \\
34.5 \\
27.3\end{array}$ & $\begin{array}{l}46.4 \\
42.4 \\
38.7 \\
51.2 \\
39.6 \\
43.2\end{array}$ & $\begin{array}{l}42.3 \\
31.6 \\
23.4 \\
42.2 \\
29.6 \\
29.7\end{array}$ & $\begin{array}{l}49.4 \\
45.7 \\
34.0 \\
52.0 \\
37.4 \\
41.0\end{array}$ & $\begin{array}{l}40.8 \\
42.6 \\
26.0 \\
39.7 \\
34.9 \\
31.8\end{array}$ & $\begin{array}{l}50.0 \\
47.4 \\
34.4 \\
54.6 \\
38.2 \\
46.1\end{array}$ & $\begin{array}{l}41.3 \\
37.2 \\
27.6 \\
40.9 \\
34.5 \\
31.8\end{array}$ & $\begin{array}{l}43.1 \\
48.0 \\
39.5 \\
52.8 \\
40.8 \\
46.3\end{array}$ \\
\hline $\begin{array}{l}\text { Mean } \\
\text { SD }\end{array}$ & $\begin{array}{r}32.6 \\
4.0\end{array}$ & $\begin{array}{r}43.6 \\
5.7\end{array}$ & $\begin{array}{r}33.1 \\
4.7\end{array}$ & $\begin{array}{r}43.6 \\
4.6\end{array}$ & $\begin{array}{r}33.1 \\
7.6\end{array}$ & $\begin{array}{r}43.2 \\
7.0\end{array}$ & $\begin{array}{r}36.0 \\
6.3\end{array}$ & $\begin{array}{r}45.1 \\
7.5\end{array}$ & $\begin{array}{r}35.6 \\
5.4\end{array}$ & $\begin{array}{r}45.1 \\
5.0\end{array}$ \\
\hline
\end{tabular}

ing procedure, except that the results from the hand adjustment procedure with the head moving (for the -5.08 - and $0.0-\mathrm{cm}$ physical motion) tend to be larger in absolute magnitude than the latter results.

The pattern of results from the head-stationary condition indicates that the apparent motion from physical motion, at the same apparent distance, increases proportionately to the physical motion. The average $\mathrm{m}^{\prime}$ (with the head stationary) for a given convergence distance, as measured either by pointing or by the hand adjustment procedure, is approximately proportional to the physical motion of the point.

An analysis of variance of the data of Table 1 shows that the apparent motion $\left(\mathrm{m}^{\prime}\right)$ of the point as measured by pointing differed significantly $(p<.01)$ as a function of the convergence distance (CD) and physical motion (m) of the point in both the headmoving $[F(1,5)=41.6$ and $F(2,10)=115.1]$ and in the head-stationary $[\mathrm{Fs}(1,5)=98.5$ and 22.3$]$ conditions. Similarly, apparent motion, as measured by the hand adjustment procedure, differed significantly $(p<.01)$ as a function of $\mathrm{CD}$ and $\mathrm{m}$ in both the head-moving $[F(1,5)=86.4$ and $F(2,10)=36.9]$ and head-stationary $[F s(1,5)=107.5$ and 40.0$]$ conditions.

Pointing directly under the point of light at its right and left extremes of motion provided two values of apparent distance $\left(D^{\prime}\right)$, as measured perpendicularly to the axis of the head motion of the observer, as well as one measure of apparent lateral motion. The data shown in Table 2 are the average of two such presentations (four measures) of $D^{\prime}$ from pointing. It will be noted from Table 2 that the point of light physically at $25 \mathrm{~cm}$ was perceived at a distance greater than $25 \mathrm{~cm}$ when the convergence was at either $25 \mathrm{~cm}$ or $40 \mathrm{~cm}$. This overperception of distance is consistent with the minus values of $\mathrm{m}^{\prime}$ shown in Table 1 with the head-moving condition for $m=0$, as measured by either the pointing or hand adjustment procedure.

A more precise test of whether or not the illusory motion from errors in perceived distance combines with nonillusory motion from physical motion can be performed by applying Equation 2 as given in the caption of Figure 1. Inserting the constants $D=25$ and $\mathrm{K}=21.2 \mathrm{~cm}$ in Equation 2 results in $\mathrm{m}=(530-$ $\left.21.2 \mathrm{D}^{\prime}+\mathrm{mD}^{\prime}\right) / 25$. Using this equation and the average $D^{\prime}$ values from pointing shown in Table 2 for each of the three values of $m(-5.08,0.0$, and $+10.16 \mathrm{~cm}$ ), predicted values of $\mathrm{m}^{\prime}$ can be calculated. These predicted values can be compared with the average $m$ ' values from pointing shown in Table 1 . The relations between predicted and obtained $m^{\prime}$ as a function of $m$ and $C D$ are shown in Figure 2. The clear

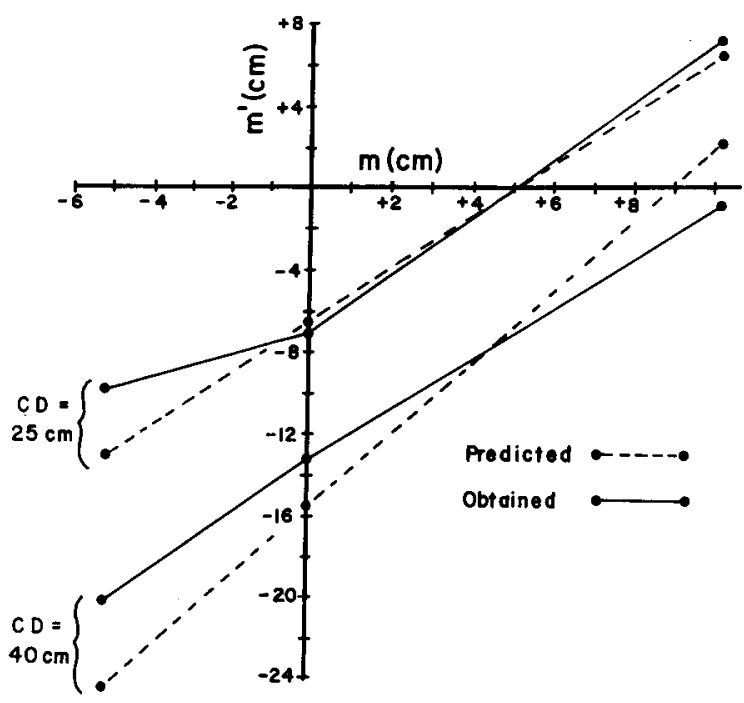

Figure 2. Predicted and obtained relation between physical $(\mathbf{m})$ and apparent $\left(m^{\prime}\right)$ concomitant motion as a function of the convergence distance $(25$ or $40 \mathrm{~cm}$ ) to the stimulus point for a constant physical distance $(25 \mathrm{~cm})$ of the stimulus from the observer. The predictions were obtained using Equation 2 and the perceived distance data (Table 2) from the pointing procedure. 
Table 3

Results From Experiment 1: Apparent Distance of the Point of Light (in Centimeters), Computed From the Null Adjustments, as a Function of Convergence Distance (in Centimeters)

\begin{tabular}{lcc}
\hline & \multicolumn{2}{c}{ Convergence Distance } \\
\cline { 2 - 3 } Observer & 25 & 40 \\
\hline 1 & 43.1 & 96.0 \\
2 & 44.8 & 64.6 \\
3 & 55.8 & 78.6 \\
4 & 48.8 & 88.3 \\
5 & 62.2 & 95.8 \\
6 & 33.5 & 47.0 \\
Mean & 48.0 & 78.4 \\
SD & 10.1 & 19.4 \\
\hline
\end{tabular}

separation between the curves as a function of $C D$ and the similarity of the predicted and obtained curves for the same values of convergence provide strong evidence for the perceptual combination of illusory and nonillusory apparent concomitant motion and for the predictive ability of the hypothesis expressed by Equation 1 and described in the caption of Figure 1 as the apparent-distance/pivot-distance hypothesis.

Apparent distance $\left(\mathrm{D}^{\prime}\right)$ can be computed also, using Equation 4 (see the caption of Figure 1), from the physical motion $(\mathrm{m})$ required in order for the point of light to appear stationary (the null adjustment) as the head was moved. The resulting average values of $D^{\prime}$ from each observer (with each $D^{\prime}$ based on four null adjustments) are shown in Table 3 . In a similar manner, using Equation 3, $\mathrm{D}^{\prime}$ can be calculated from $\mathrm{m}^{\prime}$ of the hand adjustment procedure, with overall averages obtained from the head-moving condition of $36.5 \mathrm{~cm}$ for the $25-\mathrm{cm}$ convergence and $47.5 \mathrm{~cm}$ for the $40-\mathrm{cm}$ convergence. Although all three methods of finding $D^{\prime}$, as expected, provide values of $D^{\prime}$ that increase with increases in $C D$, the average results obtained by the null adjustment procedure (Table 3 ) are considerably larger than those obtained from direct pointing (Table 2) or as calculated from the hand adjustment procedure.

\section{Discussion}

The results from Experiment 1 support the conclusion that illusory apparent concomitant motion resulting from an error in perceived distance does not qualitatively differ from apparent concomitant motion resulting from physical motion. This is shown by the modification of apparent motion from physical motion produced by the illusory concomitant motion. It also is shown more precisely in Figure 2 by applying Equation 2 .

It was noted in the caption of Figure 1 that Equation 1 and the derived Equations 2-4 contain the assumption that the perceived direction of the stimulus per unit of head motion is veridical. The $\mathrm{m}^{\prime}$ and $\mathrm{D}^{\prime}$ data from the pointing procedure shown in Tables 1 and 2 can provide a test of this assumption. If this assumption is correct, the pivot angle of Figure 1 ought to be the same whether computed from $m$ and $D$ or from $m^{\prime}$ and $D^{\prime}$. The equations for these computations are

$$
\tan \phi_{\mathrm{p}} / 2=(\mathrm{K}-\mathrm{m}) / 2 \mathrm{D}
$$

and

$$
\left.\tan \phi_{\mathrm{p}}^{\prime} / 2=\mathrm{K}^{\prime}-\mathrm{m}^{\prime}\right) / 2 \mathrm{D}^{\prime},
$$

where $\phi_{p}$ is the physical pivot angle and $\phi^{\prime}$ is the perceived pivot angle. The values of $\mathrm{m}^{\prime}$ and $D^{\prime}$ for Equation 6 are obtained from Tables 1 and 2, and the perceived head motion $\left(K^{\prime}\right)$ is assumed to be equal to the physical head motion (K). Substituting $\mathrm{m}=-5.08,0.00$, and $+10.16 \mathrm{~cm}$ (instances of Figures $1 \mathrm{~A}, 1 \mathrm{~B}$, and $1 \mathrm{C}$ or $1 \mathrm{D}$, respectively), with $\mathrm{D}=$ $25 \mathrm{~cm}$ and $\mathrm{K}=21.2 \mathrm{~cm}$, into Equation 5 results in $\phi_{\mathrm{p}}=55.5,46.0$, and $24.9 \mathrm{deg}$, respectively. For the $25-\mathrm{cm}$ convergence, the average $\mathrm{m}^{\prime}$ values from pointing are $-9.9,-7.2$, and $+7.0 \mathrm{~cm}$ (Table 1 ), and the paired average $D^{\prime}$ values from pointing are $32.6,33.1$, and $33.1 \mathrm{~cm}$ (Table 2). The resulting $\phi_{\mathrm{p}}^{\prime} \mathrm{s}$ from Equation 6 are 51.0, 46.4, and $24.2 \mathrm{deg}$, respectively. For the $40-\mathrm{cm}$ convergence, the average $\mathrm{m}^{\prime}$ values from pointing are $-20.2,-13.3$, and $-.3 \mathrm{~cm}$ (Table 1), with paired $\mathrm{D}^{\prime}$ values of 43.6 , 43.6 , and $43.2 \mathrm{~cm}$ (Table 2). The resulting $\phi_{\mathrm{p}}^{\prime} \mathrm{s}$ from Equation 6 are 50.8, 43.2, and $27.9 \mathrm{deg}$, respectively. The similarity of the results from Equations 5 and 6 provide strong support for the assumption that the perception of the change in direction of a physically stationary or physically moving point, viewed with the head moving, is quite accurate.

The accuracy of the perception of the change in direction (angle) from the observer between the leftand rightmost positions of the moving point also can be examined for the head-stationary condition. In this case also, the physical angle will be labeled $\phi$ and the perceived angle labeled $\phi^{\prime}$. For this condition, $\tan \phi / 2=m / 2 D$ and $\tan \phi^{\prime} / 2=m^{\prime} / 2 D^{\prime}$, respectively, with $m^{\prime}$ and $D^{\prime}$ specified by the average values of Tables 1 and 2 . The results for $m=5.08$ and $10.16 \mathrm{~cm}$ are $\phi=11.6$ and $23.0 \mathrm{deg}$, with $\phi^{\prime}=11.1$ and $23.8 \mathrm{deg}$ for $C D=25 \mathrm{~cm}$ and 11.9 and $24.8 \mathrm{deg}$ for $C D=40 \mathrm{~cm} .{ }^{1}$ Clearly the change in the direction of the moving point as viewed from the stationary head was accurately perceived. The relation between $\phi$ and $\phi^{\prime}$ obtained from the moving and the stationary head conditions is shown in Figure 3, with the solid line indicating complete perceptual accuracy. The continuity between the results from the head-moving and head-stationary conditions confirms the validity of the assumption that $K=K^{\prime}$. 


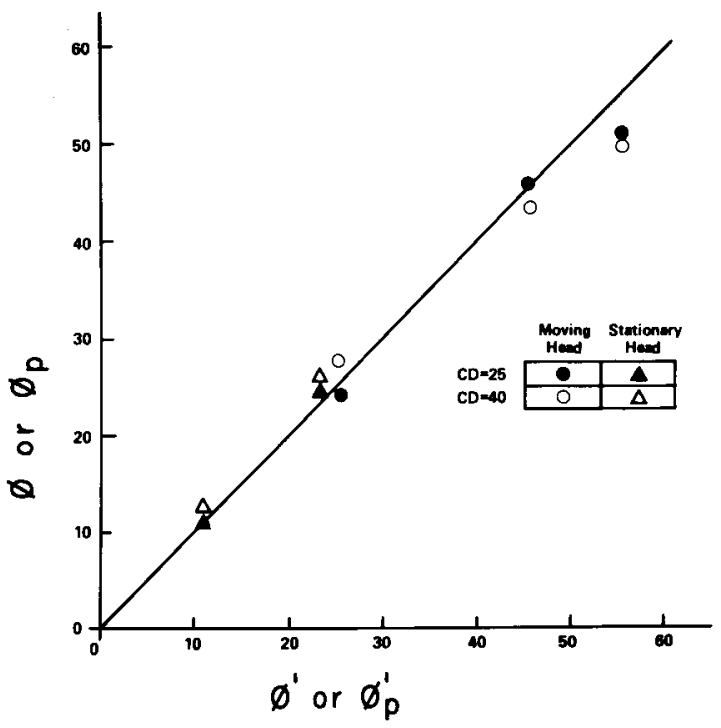

Figure 3. The relation between the physical change in direction of a point of light physically at $25 \mathrm{~cm}$ from the observer and its apparent change in direction as a function of whether the head is stationary ( $\phi$ and $\phi^{\prime}$ ) or moving ( $\phi_{p}$ and $\phi_{p}^{\prime}$ ) and whether the stimulus to convergence is to 25 or $40 \mathrm{~cm}$.

\section{EXPERIMENT 2}

\section{Method}

In Experiment 1, the perceived distance of the point of light, whether measured by pointing or computed from the hand adjustment or null adjustment procedures, was greater than the physical distance of $25 \mathrm{~cm}$, even for the case in which the convergence was at $25 \mathrm{~cm}$. This kind of result (Gogel, 1977; Gogel \& Tietz, 1979) has been explained by a tendency called the specific distance tendency (SDT), which, in the absence of all distance cues, results in a perception that the object is at a distance of about 2 or $3 \mathrm{~m}$. In the case in which limited distance information is available, some amount of error remains, as found in Experiment 1, and occurs in the direction of the 2- or 3-m distance. The SDT has been found by Owens and Leibowitz (1976) to be correlated with the resting state of convergence (found in that study to be an average distance of $1.7 \mathrm{~m}$ ). The overperception of the $25-\mathrm{cm}$ distance of the stimulus in Experiment 1 thus could be explained by a tendency for the convergence of the eyes to assume a value between that required by the physical distance of the point and that of the resting state of convergence. This error in convergence (a fixation disparity) would then be responsible for the error in perceived distance. This possibility is examined in Experiment 2.

In Experiment 2, fixation disparity is measured by a nonius procedure in which three points of light are presented. An upper point is viewed by one eye only and a lower point by the other eye only, with the center point viewed binocularly. If no fixation disparity is present, the points will appear to be aligned vertically when physically they are aligned vertically. A fixation disparity will produce an error in perceived vertical alignment. From this error, the amount and direction of fixation disparity can be calculated.

\section{Observers}

The six observers of Experiment 1 also were the observers in Experiment 2.

\section{Apparatus}

Head-motion apparatus. The head-position apparatus for the head-moving and head-stationary conditions was the same as in Experiment 1, except that the pause at the extremes of lateral motion did not occur. Again, for the head-motion conditions, the head moved repetitively left and right through a distance of $21.2 \mathrm{~cm}$ and the arrival of the head at an extreme of motion was paced by a buzzer sounding every $1.5 \mathrm{sec}$. For the head-stationary condjtions, the apparatus was pinned in place at the observation center.

Nonius apparatus. The binocularly viewed point of light always was physically stationary throughout Experiment 2 and, as in Experiment 1 , was always at a physical distance of $25 \mathrm{~cm}$ from the observer, with the convergence to this point adjusted (in a manner to be described) to a distance of either 25 or $40 \mathrm{~cm}$. As in Experiment 1 , the output from a linear potentiometer coupled to the bite-board assembly informed the computer of the lateral position of the head. The stimulus display at the $25-$ and $40-\mathrm{cm}$ convergence is illustrated in Figure 4. Consider first the display for the $25-\mathrm{cm}$ convergence distance illustrated in Figure 4A. A single binocularly observed point of light, located $25 \mathrm{~cm}$ from the observer at eye level at the center of the display, was covered by a neutral density filter to equate the brightness of this point to that of the nonius points. The nonius points of light, one above and the other below the binocularly viewed point, were covered with oppositely oriented, polarizing filters. Polarizing filters of the appropriate orientation also were in goggles worn by the observer so that, although the center point was seen binocularly, the upper nonius point was seen only by the left eye and the lower nonius point only by the right eye. A knob near the observer's position allowed the observer to move the nonius points laterally in opposite directions, as is indicated by the solid and dashed arrows. The vertical displacement of each nonius point from the binocularly viewed point was $.4 \mathrm{~cm}$.

The display for the $40-\mathrm{cm}$ convergence distance is illustrated in Figure 4B. Here, the binocularly observed point of light was produced by two points laterally separated. This lateral separation was adjusted by the experimenter, consistent with the internodal distance of the observer, to provide the convergence distance of $40 \mathrm{~cm}$. Again, the upper nonius point was visible only to the left eye and the lower nonius point only to the right eye. When the middle points were binocularly fused, the stimulus on the eye was identical to that for the $25-\mathrm{cm}$ accommodation, but the stimulus for convergence was to a distance of $40 \mathrm{~cm}$. Again, as shown by the solid and dashed arrows, the nonius points could be moved

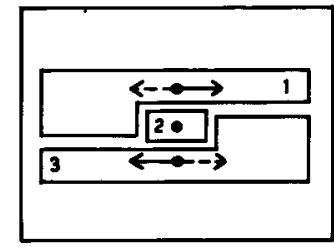

A

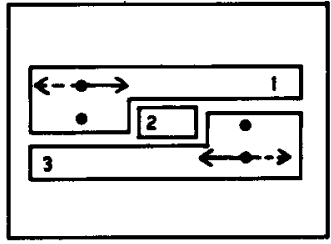

B
Figure 4. The location of neatral density and polariaing filters on the display surface in order to present the center point of light at a convergence distance of 25 (Figure $4 \mathrm{~A}$ ) or $40 \mathrm{~cm}$ (Figare 4B) in Experiment 2. Filter 1 is a polarining filter that presents an image of the upper point to the left eye only. Futer 2 is a neutral density filter that presents an image of the center point to both eyes for the $25-\mathrm{cm}$ convergence distance. Filter 3 is a polarizing filter that presents an image of the lower point to the right eye only. The upper and lower (monocularly viewed) points, as indicated by the solid and dashed arrows, are adjustable laterally in opposite directions. 
laterally in opposite directions. Nothing was visible except the binocularly fused point and the two nonius points.

Both the head-moving and head-stationary conditions were used. The binocularly viewed point of light always was physically stationary and always was visible continuously during a trial. In order to measure the fixation disparity during several positions of the head, the two nonius points, when presented, were visible only for $.19 \mathrm{sec}$. These presentations occurred at the middle, left, or right positions of the head motion. On a single trial, the nonius points were momentarily presented (flashed) whenever the head in the bite-board assembly moved in a particular direction (left or right) and reached one of three possible selected positions (defined as occurring at $3 / 16,1 / 2$, or $13 / 16$ of a right or left motion of the head). Flashes of the nonius points at the selected position were presented during six successive right-left or left-right head movements, and the task of the observer was to adjust the control knob between successive nonius flashes (occurring at 3-sec intervals) until the three points appeared vertically aligned. The observer then pressed a knob that recorded in the computer the lateral separation of the upper and lower nonius points at the final adjustment. The hand adjustment procedure also was used as in Experiment 1 to measure the magnitude of the apparent concomitant motion at the two convergence distances.

\section{Procedure}

The variables of Experiment 2 were (1) the distance of convergence $(25$ or $40 \mathrm{~cm}),(2)$ whether the head was stationary or moving, (3) the head position at which the nonius flashes occurred (right, middle, or left), and (4) the direction of head motion (right or left) at the time the flashes were presented. All trials were completed at one convergence distance and then the other, with the order in which the convergence distances were presented counterbalanced between observers. The head-motion condition always preceded the head-stationary condition. The order of presentation of the remaining two variables was counterbalanced between observers. All observers received all values of the variables.

For the head-moving conditions, on each trial the observer was presented with six flashes of the nonius points as controlled by the computer. One flash occurred each time the head reached the designated portion of its travel in the designated direction of motion. The procedure was as follows. The experimenter moved the adjustment knob so that the three points were clearly not aligned vertically and then opened the observation aperture. The observer, wearing the polarizing goggles, moved his or her head laterally while binocularly fixating the center point of light. Following the first momentary presentation of the nonius points, the observer adjusted the knob in the direction of apparent vertical alignment of the points. Upon perceiving the next flash, another adjustment was made, with the successive remaining flashes used to fine-tune the perceived vertical alignment of the three points. The final alignment was recorded on the computer and the shutter was closed. Following this procedure, a nonius adjustment was obtained at the other two positions of the head-motion cycle. Following this, another trial was presented, retaining the nonius adjustment completed last. On this additional trial, the observer noted the direction (with or against the direction of head motion) and the amount of apparent concomitant motion of the binocularly viewed point. The viewing aperture then was closed and the light in the observation booth was turned on. After having indicated verbally the direction of the apparent motion, the observer adjusted the separation of the rods of the hand adjustment apparatus to indicate the lateral extent of the apparent motion.

A similar procedure was followed with the head-stationary condition, except that only a single set of six flashes of the nonius adjustment was presented and, since there was no reason to expect the point to appear to move, the hand adjustment apparatus was not used. Practice, given before any of the experimental data was collected, consisted of completing the first three nonius alignments in the first head-motion condition, followed by the hand adjustment and the single nonius alignment with the head-stationary condition. After presenting all the conditions to a particular observer, the entire experiment was repeated for that observer, so that two measures were obtained for each observer on each particular combination of conditions. The observer's score was the average of these.

\section{Results}

All six observers perceived the binocularly fixated point of light as moving oppositely to the direction of the head motion. The average result from the hand adjustments was $-9.4 \mathrm{~cm}$ for the convergence distance of $25 \mathrm{~cm}$ and $-13.4 \mathrm{~cm}$ for the convergence distance of $40 \mathrm{~cm}$. Although the absolute magnitudes of these averages are less than those obtained in Experiment 1 under the same conditions $(-12.8$ and $-21.4 \mathrm{~cm}$ ), it is clear that, as in Experiment 1, substantial amounts of illusory apparent concomitant motion opposite to the head motion were obtained in Experiment 2.

The results from the nonius adjustments are shown in Table 4. A plus nonius (a plus fixation disparity) indicates that the actual convergence was to a distance greater than the distance of the stimulus to convergence. A minus nonius (a minus fixation disparity) indicates that the actual convergence was to a distance less than the distance of the stimulus to convergence. Table 4 also gives the linear error in the actual convergence distance (FE) in centimeters and the angular fixation disparity (FD) in minutes of arc, as computed from the nonius measures and using the average internodal distance of the observers. The value of $\mathrm{m}^{\prime}$ shown in Table 4 is the apparent concomitant motion expected from the fixation disparity for the $25-\mathrm{cm}$ convergence condition, computed from Equation 2 with $m=0$. In this case, $m^{\prime}=k\left(D-D^{\prime}\right) / D$ with the linear fixation error specifying $D-D^{\prime}$. In other words, the portion of Table 4 indicating predicted $\mathrm{m}^{\prime}$ gives the apparent concomitant motion of the binocularly observed point, at the physical and convergence stimulus distance of $25 \mathrm{~cm}$, that is predicted if fixation disparity were the sole source of error in perceiving the point at a distance greater than its physical distance. These values of $\mathrm{m}^{\prime}$, predicted from the fixation disparity, however, are unable to explain the illusory apparent concomitant motion $\left(m^{\prime}\right)$ measured with the hand adjustment procedure in Experiment 2 (or Experiment 1) or with the pointing procedure in Experiment 1. Although the direction of the fixation disparity for the $25-\mathrm{cm}$ convergence is consistent with that expected from the resting state of convergence, the apparent concomitant motion attributable to this fixation disparity is trivial compared with the apparent concomitant motion actually obtained. Unlike the $25-\mathrm{cm}$ distance, the fixation error at the $40-\mathrm{cm}$ convergence distance was not in the direction expected from the resting state of convergence. This possibly can be explained by 
Table 4

Results From Experiment 2: Lateral Separation in Centimeters Between the Upper and Lower Nonius Points Required to Perceive the Points as Vertically Aligned as a Function of the Head Location (Left, Middle, or Right) at Which the Nonius Flashes Occurred and the Direction (Left or Right) in Which the Head was Moving

\begin{tabular}{|c|c|c|c|c|c|c|c|}
\hline \multirow[b]{3}{*}{ Observer } & \multicolumn{6}{|c|}{ Moving Head } & \multirow[b]{3}{*}{$\begin{array}{c}\text { Stationary } \\
\text { Head* }\end{array}$} \\
\hline & \multicolumn{3}{|c|}{ Head Moving Left } & \multicolumn{3}{|c|}{ Head Moving Right } & \\
\hline & $\begin{array}{c}\text { Nonius } \\
\text { Left }\end{array}$ & $\begin{array}{l}\text { Nonius } \\
\text { Middle }\end{array}$ & $\begin{array}{c}\text { Nonius } \\
\text { Right }\end{array}$ & $\begin{array}{c}\text { Nonius } \\
\text { Left }\end{array}$ & $\begin{array}{l}\text { Nonius } \\
\text { Middle }\end{array}$ & $\begin{array}{c}\text { Nonius } \\
\text { Right }\end{array}$ & \\
\hline & \multicolumn{7}{|c|}{ Convergence Distance $=25 \mathrm{~cm}$} \\
\hline $\begin{array}{l}1 \\
2 \\
3 \\
4 \\
5 \\
6\end{array}$ & $\begin{array}{l}+.061 \\
+.003 \\
+.007 \\
-.026 \\
+.019 \\
+.021\end{array}$ & $\begin{array}{l}+.051 \\
+.008 \\
+.147 \\
+.035 \\
-.041 \\
-.048\end{array}$ & $\begin{array}{l}+.108 \\
+.139 \\
+.145 \\
-.032 \\
+.008 \\
+.003\end{array}$ & $\begin{array}{r}+.101 \\
+.104 \\
+.133 \\
+.043 \\
.000 \\
+.076\end{array}$ & $\begin{array}{r}+.039 \\
+.049 \\
-.011 \\
+.077 \\
-.017 \\
+.103\end{array}$ & $\begin{array}{l}+.052 \\
+.058 \\
+.041 \\
-.126 \\
+.023 \\
+.026\end{array}$ & $\begin{array}{r}+.083 \\
+.147 \\
+.057 \\
+.002 \\
-.010 \\
-.041\end{array}$ \\
\hline $\begin{array}{l}\text { Mean } \\
\text { SD } \\
\text { FE } \\
\text { FD } \\
\text { m }^{\prime}\end{array}$ & $\begin{array}{l}+.014 \\
.029 \\
+.06 \\
+1.9 \\
-.05\end{array}$ & $\begin{array}{r}+.025 \\
.072 \\
+.10 \\
+3.4 \\
-.09\end{array}$ & $\begin{array}{l}+.062 \\
.078 \\
+.25 \\
+8.4 \\
-.21\end{array}$ & $\begin{array}{c}+.076 \\
.048 \\
+.31 \\
+10.3 \\
-.26\end{array}$ & $\begin{array}{l}+.040 \\
.048 \\
+.16 \\
+5.4 \\
-.14\end{array}$ & $\begin{array}{l}+.013 \\
.069 \\
+.05 \\
+1.8 \\
-.04\end{array}$ & $\begin{array}{l}+.039 \\
.069 \\
+.16 \\
+5.3 \\
-.13\end{array}$ \\
\hline $\begin{array}{l}\text { FD } \\
\mathrm{m}^{\prime}\end{array}$ & \multicolumn{7}{|c|}{ Convergence Distance $=40 \mathrm{~cm}$} \\
\hline $\begin{array}{l}1 \\
2 \\
3 \\
4 \\
5 \\
6\end{array}$ & $\begin{array}{l}+.080 \\
+.016 \\
-.050 \\
-.059 \\
-.091 \\
-.058\end{array}$ & $\begin{array}{l}-.034 \\
+.049 \\
+.016 \\
-.005 \\
-.140 \\
-.026\end{array}$ & $\begin{array}{l}+.107 \\
-.013 \\
-.022 \\
-.093 \\
-.044 \\
-.048\end{array}$ & $\begin{array}{r}-.023 \\
-.208 \\
+.030 \\
-.088 \\
+.004 \\
+.029\end{array}$ & $\begin{array}{l}+.038 \\
+.025 \\
+.047 \\
-.069 \\
-.050 \\
+.010\end{array}$ & $\begin{array}{l}+.068 \\
-.263 \\
-.084 \\
-.148 \\
-.040 \\
+.009\end{array}$ & $\begin{array}{l}+.061 \\
+.115 \\
+.012 \\
+.009 \\
-.310 \\
-.076\end{array}$ \\
\hline $\begin{array}{l}\text { Mean } \\
\text { SD } \\
\text { FE } \\
\text { FD }\end{array}$ & $\begin{array}{c}-.027 \\
.063 \\
-.17 \\
-2.2\end{array}$ & $\begin{array}{c}-.023 \\
.065 \\
-.15 \\
-1.9\end{array}$ & $\begin{array}{c}-.019 \\
.068 \\
-.12 \\
-1.6\end{array}$ & $\begin{array}{c}-.043 \\
.092 \\
-.28 \\
-3.7\end{array}$ & $\begin{array}{l}.000 \\
.048 \\
.00 \\
.0\end{array}$ & $\begin{array}{c}-.076 \\
.118 \\
-.49 \\
-6.6\end{array}$ & $\begin{array}{c}-.032 \\
.151 \\
-.21 \\
-2.7\end{array}$ \\
\hline
\end{tabular}

Note-Also shown are the average linear fixation error (FE; in centimeters) and angular fixation disparity (FD; in minutes of arc) and the apparent concomitant motion ( $\mathrm{m}^{\prime}$; in centimeters) predicted from these. ${ }^{*}$ Nonius middle.

the discrepancy between accommodation and convergence that was present at this convergence distance.

The average fixation disparities were almost identical for the head-moving and head-stationary conditions. For the $25-\mathrm{cm}$ convergence stimulus, these were 5.2 and $5.3 \mathrm{~min}$ of arc, respectively, and for the $40-\mathrm{cm}$ convergence stimulus, both were $2.7 \mathrm{~min}$ of arc. There were, however, significant differences in the patterns of fixation error in the head-motion conditions as a function of the head position at the time the nonius judgments were obtained. According to an analysis of variance of the nonius data, convergence distance and the interaction of direction of head motion and location were significant $[F(1,5)$ $=24.5, \mathrm{p}<.01$, and $F(2,10)=4.58, \mathrm{p}<.05$, respectively]. There is some indication that the fixation error tended to be greatest just after the observer started to reverse the direction of head motion. It is possible that, at that moment, the head was undergoing the greatest acceleration, despite the instructions to move at a constant velocity. Nevertheless, the magnitudes of the fixation disparity at all three locations were small.

\section{Discussion}

The fixation disparities measured in Experiment 2 are far too small to support the hypothesis that fixation disparity in the direction of the resting state of convergence was the determiner of the error in perceived distance found with the $25-\mathrm{cm}$ convergence distance. It is of interest that, under the conditions of this study, the fixation disparity obtained with the head moving was not substantially different from that obtained with the head stationary.

Ivanoff and Bourdy (1954) found, under low levels of stimulus illumination, that the convergence of the eyes was in error in the direction of an intermediate distance from the observer. In that study, a monocular point of fixation was displaced $8 \mathrm{deg}$ from the direction of the binocular test object. However, as shown by Francis and Owens (Note 1), as the directional displacement of the fixation from the test object decreases, the convergence error in the direction of the resting state also decreases. In the present experiment, in which the physically stationary, binocularly fixated test light was viewed foveally while the head moved, the fixation error was far too small 
to account for the robust concomitant motion perceived by the observer. The error in convergence in the direction of the resting state clearly is insufficient to explain the error in perceived distance and thus the illusory concomitant motion obtained under these conditions. A different concept, for example, that of a specific distance tendency, is required. It follows that the resting state of convergence and the specific distance tendency are not the same phenomenon.

\section{CONCLUSIONS}

A number of conclusions are consistent with the data of Experiment 1: (1) The apparent motion of a physically stationary object concomitant with a lateral motion of the head is not paradoxical but, instead, is perceptually indistinguishable from apparent motion resulting from the physical motion of the object. (2) The apparent distance of a point of light as measured by the pointing procedure is substantially the same whether the change in the apparent direction to the point is the result of head or of point motion. Unlike the study by Gogel and Tietz (1979) and consistent with the study by Hagen and Teghtsoonian (1981), absolute motion parallax in the present study was not even partially effective as a cue of egocentric distance. (3) The perception of direction of a stationary or moving object viewed with the head moving or of a moving object viewed with the head stationary is substantially veridical. This conclusion is important for the ready application of the apparentdistance/pivot-distance hypothesis specified by Equation 1. (4) The null adjustment procedure resulted in measures of perceived distance considerably larger than measures of perceived distance from pointing or from the hand adjustment procedure. However, the direction of the measured changes in perceived distance as a function of convergence was the same with all three procedures.

Several conclusions also are consistent with the data of Experiment 2: (1) The apparent concomitant motion of a physically stationary test point can occur in the absence of a commensurate error in convergence (fixation disparity). (2) The specific distance tendency is not explained by the resting state of convergence. (3) The obtained effect of apparent distance upon apparent concomitant motion supports the assertion (Gogel, 1980) that apparent concomitant motion cannot be explained solely by retinal motion, that is, that apparent concomitant motion is not a direct response to motion on the retina. (5) The magnitude of the fixation disparity (usually less than $10 \mathrm{~min}$ of arc) at near-convergence distances is about the same whether the head moves or is stationary.

\section{REFERENCE NOTE}

1. Francis, E. L., \& Owens, D. A. The accuracy of convergence for peripheral stimuli. Paper presented at the meeting of the Optical Society of America, Sarasota, Florida, May 1980.

\section{REFERENCES}

GogeL, W. C. An indirect method of measuring perceived distance from familiar size. Perception \& Psychophysics, 1976, 20, 419-429.

GoGel, W. C. An indirect measure of perceived distance from oculomotor cues. Perception \& Psychophysics, 1977, 21, 3-11.

Goges, W. C. The sensing of retinal motion. Perception \& Psychophysics, 1980, 28, 155-163.

Gogel, W. C. Perceived depth is a necessary factor in apparent motion concomitant with head motion: A reply to Shebilske and Proffitt. Perception \& Psychophysics, 1981, 29, 173-177.

Gogel, W. C., \& Tietz, J. D. Absolute motion parallax and the specific distance tendency. Perception \& Psychophysics; 1973, 13, 284-292.

Gogel, W. C., \& Tietz, J. D. A comparison of oculomotor and motion parallax cues of egocentric distance. Vision Research, $1979,19,1161-1170$.

Hagen, M. A., \& Teghtsoonian, M. The effects of binocular and motion-generated information on the perception of depth and height. Perception \& Psychophysics, 1981, 30, 257-265.

IvanofF, A., \& Bourdy, C. Le comportement de la convergence en vision nocturne. Annales d'Optique Oculaire, 1954, 3, 70-74.

OWEns, D. A., \& Leibowitz, H. W. Oculomotor adjustments in darkness and the specific distance tendency. Perception \& Psychophysics, 1976, 20, 2-9.

Shebilske, W. L., \& ProffitT, D. R. The priority of perceived distance for perceiving motion has not been demonstrated: Critical comments on Gogel's "The sensing of retinal motion." Perception \& Psychophysics, 1981, 29, 170-172.

\section{NOTE}

1. The apparent distance of the point of light in Table 2 is measured perpendicularly to the axis of the head motion of the observer. To obtain the apparent distance measured along the diagonal from the extreme head positions to the point of light, the values of Table 2 must be multiplied by the secant of $\phi_{p}^{\prime} / 2$ for the head-moving data and by the secant of $\phi^{\prime} / 2$ for the head-stationary data. Only for the larger values of $\phi_{p}$ is this multiplier appreciably greater than unity in this study (a maximum of 1.11).

(Manuscript received February 23, 1982; revision accepted for publication May 24,1982 .) 